\title{
OPTIMALISASI PRODUKSI MENGGUNAKAN METODE INTEGER PREEMPTIVE GOAL PROGRAMMING (Studi Kasus: UD Citra Ayu Bali)
}

\author{
Vinsentia Revica Bella Rossary ${ }^{1 \S}$, I Wayan Sumarjaya ${ }^{2}$, Kartika Sari $^{3}$ \\ ${ }^{1}$ Program Studi Matematika, Fakultas MIPA - Universitas Udayana [Email: vincent.revica@gmail.com] \\ ${ }^{2}$ Program Studi Matematika, Fakultas MIPA - Universitas Udayana [Email: sumarjaya@unud.ac.id] \\ ${ }^{3}$ Program Studi Matematika, Fakultas MIPA - Universitas Udayana [Email: sarikartika@unud.ac.id ] \\ ${ }^{\S}$ Corresponding Author
}

\begin{abstract}
One of the home industry in Bali that produces beauty products is UD Citra Ayu Bali. This company has five types of body scrub scent, where the five types of body scrub has a different number of requests. UD Citra Ayu Bali has been doing production activities only when there is demand, so the production process is still less than optimal because it is still done randomly or unplanned. Therefore, this research is done to make production planning body scrub UD Citra Ayu Bali by determining the prediction of the number of products that must be produced every week so that the production process becomes optimal. By using the integer preemptive goal programming method, the optimal production number of the five types scrubs for 12 consecutive weeks is 212 pieces, 548 pieces, 328 pieces, 474 pieces, 506 pieces, 455 pieces, 103 pieces, 381 pieces, 63 pieces, 547 pieces, 59 pieces, and 454 pieces.
\end{abstract}

\section{Keywords: Preemptive Goal Programming Method, Integer, Optimization, Beauty Product}

\section{PENDAHULUAN}

Perencanaan produksi adalah suatu proses untuk menentukan target hasil produksi, biaya produksi, pemanfaatan bahan atau sumber daya, dan pengiriman produk sesuai pesanan konsumen pada suatu perusahaan. Perencanaan produksi bertujuan untuk memenuhi permintaan konsumen dengan tetap mempertahankan ketersediaan sumber daya (Leachman, 2013). Dalam kegiatan produksi, hal yang perlu diperhatikan adalah jumlah permintaan konsumen terhadap produk tersebut. Akan tetapi, adanya permasalahan perubahan kondisi dan situasi pada masa yang akan datang menghadapkan perusahaan pada masalah kuantitas penjualan produk yang fluktuatif. Hal ini berpengaruh pada pengambilan keputusan suatu perusahaan dalam memproduksi barang. Pengambilan keputusan tersebut akan menjadi lebih baik apabila diketahui jumlah permintaan yang akan datang dengan meramalkan jumlah permintaan tersebut.

Selain memerlukan peramalan, perencanaan produksi juga memerlukan optimalisasi produksi. Salah satu metode optimalisasi produksi adalah metode goal programming. Goal programming merupakan sebuah teknik yang telah di-kembangkan untuk menganalisis dan me-nyelesaikan persoalan optimalisasi yang me-libatkan banyak tujuan. Salah satu bagian dari metode goal programming adalah integer preemptive goal programming. Metode integer preemptive goal programming merupakan metode optimalisasi yang nilai keputusannya berupa bilangan bulat, dapat mengoptimalkan tujuan yang lebih dari satu dan memiliki prioritas dalam mengoptimalkannya (Surachman \& Astuti, 2015).

Penelitian tentang optimalisasi produksi dengan metode goal programming telah dilakukan oleh Deviyanti, dkk. (2015) yang melakukan penelitian tentang optimalisasi perencanaan produksi UD Dodol Made Merta Tejakula dengan menggunakan metode peramalan ARIMA dan metode preemptive goal programming. Pada penelitian yang telah 
dilakukan oleh Deviyanti, dkk. (2015) tidak memperhatikan pengaruh musiman dalam peramalannya. Selain itu, penelitian tersebut tidak memperhatikan nilai keputusan dalam optimalisasinya bernilai bulat atau tidak. Berbeda dengan penelitian yang dilakukan Deviyanti, dkk. (2015), penelitian ini memperhatikan pengaruh musiman pada peramalannya dan nilai keputusan yang bulat.

Penelitian ini bertujuan untuk membuat perencanaan produksi dengan peramalan menggunakan metode Holt-Winter's exponential smoothing dan optimalisasi dengan menggunakan metode integer preemptive goal programming. Studi kasus yang diambil adalah perencanaan produksi body scrub pada UD Citra Ayu Bali. UD Citra Ayu Bali merupakan salah satu industri rumahan di Bali yang memproduksi produk kecantikan seperti lulur bubuk, body scrub, massage oil, dan berbagai macam produk lain. Perusahaan ini memiliki lima jenis aroma body scrub, yakni body scrub frangipani, body scrub bengkoang, body scrub avocado, body scrub strawberry, dan body scrub green tea. UD Citra Ayu Bali selama ini melakukan kegiatan produksi hanya saat ada permintaan, sehingga proses produksi masih kurang optimal karena masih dilakukan secara acak atau tidak terencana. Oleh karena itu, penelitian ini dilakukan untuk membuat perencanaan produksi body scrub UD Citra Ayu Bali dengan mengetahui jumlah produksi optimal dari lima jenis scrub UD Citra Ayu Bali menggunakan metode integer preemptive goal programming.

Bentuk umum dari fungsi tujuan pada preemptive goal programming (Siswanto, 2007):

Minimumkan

$$
\sum_{i=1}^{m} P_{i}\left(d_{i}^{+}+d_{i}^{-}\right)
$$

dengan $\quad d_{i}^{+} \geq 0, d_{i}^{-} \geq 0 . \quad P_{i}(i=1,2, \ldots, m)$ merupakan notasi untuk menandai urutan prioritas sasaran yang hendak dicapai, $d_{i}^{+}$ menyatakan besar penyimpangan positif, $d_{i}^{-}$ menyatakan besar penyimpangan negatif. Sasaran yang ditetapkan akan tercapai bila variabel deviasional $\left(d_{i}^{-} \& d_{i}^{+}\right)$bernilai nol (0).

\section{METODE PENELITIAN}

Penelitian ini dilakukan di UD Citra Ayu Bali. Data yang digunakan dalam penelitian ini merupakan data produksi harian yang kemudian diubah menjadi data prouksi mingguan scrub per pieces yang diambil pada UD Citra Ayu Bali dari bulan Agustus 2015 sampai Agustus 2017.

Variabel yang digunakan dalam penelitian ini adalah:

1. Jumlah permintaan mingguan (selama 12 minggu dalam pieces), lima jenis scrub UD Citra Ayu Bali yaitu scrub frangipani, scrub bengkoang, scrub avocado, scrub greentea dan scrub strawberry.

2. Jumlah produksi masing-masing scrub dalam pieces $\quad\left(x_{i}, i=1,2,3,4,5\right) . \quad$ Variabel $\quad x_{1}$ menyatakan jumlah produksi scrub frangipani, $x_{2}$ menyatakan jumlah produksi scrub bengkoang, $x_{3}$ menyatakan jumlah produksi scrub avocado, $x_{4}$ menyatakan jumlah produksi scrub greentea, dan $x_{5}$ menyatakan jumlah produksi scrub strawberry.

Selanjutnya, langkah-langkah dalam penelitian ini adalah sebagai berikut : (1) meramalkan permintaan body scrub UD Citra Ayu Bali dengan menggunakan metode HoltWinter exponential smoothing; (2) Menetapkan variabel keputusan; (3) Memodelkan data hasil peramalan permintaan body scrub, keuntungan masing-masing body scrub dan biaya produksi body scrub ke dalam fungsi kendala; (4) Menetapkan urutan tingkat kepentingan prioritas; (5) Menambahkan variabel deviasional yang menampung nilai penyimpangan dari target kedalam fungsi kendala; (6) Merumuskan fungsi tujuan yang meminimumkan variabel deviasional; (7) Mencari solusi dari permasalahan; (8) Interpretasi hasil.

\section{HASIL DAN PEMBAHASAN}

\section{A. Peramalan Jumlah Permintaan Scrub UD Citra Ayu Bali}

Data permintaan kelima jenis scrub yang diproduksi UD Citra Ayu Bali selama bulan Agustus 2015 sampai bulan Agustus 2017 diramalkan dengan bantuan program $\mathrm{R}$, sehingga diperoleh hasil ramalan telah 
dibulatkan sebagai berikut:

Tabel 1. Hasil Ramalan yang Telah Dibulatkan

\begin{tabular}{|c|c|c|c|c|c|}
\hline \multirow{2}{*}{$\begin{array}{c}\text { Periode } \\
\text { (minggu })\end{array}$} & \multicolumn{5}{|c|}{ Jenis scrub } \\
\cline { 2 - 6 } & $x_{1}$ & $x_{2}$ & $x_{3}$ & $x_{4}$ & $x_{5}$ \\
\hline 1 & 31 & 52 & 53 & 42 & 34 \\
\hline 2 & 71 & 82 & 67 & 64 & 74 \\
\hline 3 & 50 & 71 & 129 & 67 & 67 \\
\hline 4 & 108 & 119 & 118 & 125 & 107 \\
\hline 5 & 145 & 114 & 118 & 109 & 105 \\
\hline 6 & 89 & 118 & 128 & 163 & 108 \\
\hline 7 & 9 & 25 & 20 & 28 & 21 \\
\hline 8 & 77 & 87 & 84 & 87 & 77 \\
\hline 9 & 7 & 16 & 21 & 13 & 6 \\
\hline 10 & 147 & 159 & 153 & 157 & 144 \\
\hline 11 & 7 & 19 & 13 & 17 & 3 \\
\hline 12 & 115 & 124 & 115 & 94 & 79 \\
\hline
\end{tabular}

Hasil ramalan pada Tabel 1 akan digunakan sebagai batasan optimalisasi prioritas pertama.

\section{B. Optimalisasi Produksi Kelima Jenis Scrub UD Citra Ayu Bali}

\section{Menetapkan variabel keputusan}

Variabel keputusan dalam penelitian ini adalah $x_{i, j}$, dengan $i=1,2,3,4,5$ yang menyatakan jenis scrub dan $j=1,2,3, \ldots, 12$ yang menyatakan periode (minggu ke-). $i=1$ menyatakan scrub frangipani, $i=2$ menyatakan scrub bengkoang, $i=3$ menyatakan scrub avocado, $i=4$ menyatakan scrub green tea, dan $i=5$ menyatakan scrub strawberry.

\section{Memodelkan fungsi kendala}

Dengan menggunakan data persediaan bahan baku dan data penggunaan bahan baku dari UD Citra Ayu Bali, diperoleh fungsi kendala bahan baku scrub UD Citra Ayu Bali sebagai berikut: Scrub kasar

$$
\begin{aligned}
10 x_{1, j}+10 x_{2, j} & +10 x_{3, j}+10 x_{4, j}+10 x_{5, j} \\
\leq & 10.000
\end{aligned}
$$

Ekstrak bunga chamomile

Air

$$
\begin{gathered}
0,25 x_{1, j}+0,25 x_{2, j}+0,25 x_{3, j}+0,25 x_{4, j} \\
+0,25 x_{5, j} \leq 500
\end{gathered}
$$

$$
\begin{array}{r}
250 x_{1, j}+250 x_{2, j}+250 x_{3, j}+250 x_{4, j} \\
+250 x_{5, j} \leq 200.000
\end{array}
$$

Bahan pembuat cream

$$
\begin{gathered}
62,5 x_{1, j}+62,5 x_{2, j}+62,5 x_{3, j}+62,5 x_{4, j} \\
+62,5 x_{5, j} \leq 35.000
\end{gathered}
$$

Pewarna Hijau

$$
0,05 x_{3, j}+0,05 x_{4, j} \leq 7
$$

Pewarna Merah Muda

Ekstrak Bengkoang

$$
0,05 x_{5, j} \leq 7
$$

Ekstrak Avocado

$$
0,25 x_{2, j} \leq 30
$$

Ekstrak Green Tea

$$
0,25 x_{3, j} \leq 125
$$

Ekstrak Strawberry

$$
0,25 x_{4, j} \leq 50
$$

Parfum Frangipani

$$
0,25 x_{5, j} \leq 200
$$

Parfum Bengkoang

$$
1,25 x_{1, j} \leq 185
$$

Parfum Avocado

$$
1,25 x_{2, j} \leq 250
$$

Parfum Green Tea

$$
1,25 x_{3, j} \leq 125
$$

Parfum Strawberry

$$
1,25 x_{4, j} \leq 170
$$

$$
1,25 x_{5, j} \leq 185
$$

\section{Merumuskan fungsi tujuan}

Terdapat 3 tujuan yang ingin dicapai UD Citra Ayu Bali, yaitu memenuhi permintaan konsumen, mendapat keuntungan yang maksimal dan meminimalkan biaya produksi. Ketiga tujuan tersebut dibentuk menjadi fungsi tujuan dengan prioritas sebagai berikut :

a. Prioritas pertama adalah terpenuhinya target jumlah permintaan scrub yang akan diproduksi, yang dinyatakan kedalam $P_{i}$ dengan $i=1$. Pemenuhan jumlah target yang akan diproduksi mengacu pada hasil ramalan masing-masing dari kelima jenis scrub. Hasil peramalan tersebut akan menjadi fungsi pembatas jumlah permintaan kelima jenis scrub, yang dinyatakan kedalam $r_{i, j}$. Prioritas pertama dirumuskan ke dalam fungsi tujuan sebagai berikut : $x_{i, j}+d_{i, j}^{-} \geq r_{i, j}$.

b. Prioritas kedua adalah terpenuhinya target memaksimalkan keuntungan usaha dagang sekurang-kurangnya $\quad \mathrm{Rp} \quad 4.500 .000$. Keuntungan penjualan per-pieces kelima jenis scrub secara berturut-turut dari scrub frangipani, bengkoang, avocado, green tea, dan strawberry adalah Rp 5.400, Rp 5.100, 
Rp 5.300, Rp 4.900, dan Rp 5.300. Sehingga, prioritas kedua dirumuskan ke dalam fungsi tujuan sebagai berikut :

$$
\begin{aligned}
5.400 x_{1, j}+5.100 x_{2, j}+5.300 x_{3, j} \\
+4.900 x_{4, j}+5.300 x_{5, j} \\
+d_{6, j}^{-} \geq 4.500 .000
\end{aligned}
$$

c. Prioritas ketiga adalah terpenuhinya target meminimalkan biaya produksi, yaitu kurang dari Rp 7.000.000. Biaya produksi perpieces kelima jenis scrub secara berturutturut dari scrub frangipani, bengkoang, avocado, green tea, dan strawberry adalah Rp 8.600, Rp 8.900, Rp 8.700, Rp 9.100, dan Rp 8.700. Sehingga, prioritas ketiga dirumuskan ke dalam fungsi tujuan sebagai berikut :

$$
\begin{aligned}
8.600 x_{1, j}+8.900 x_{2, j}+8.700 x_{3, j} \\
+9.100 x_{4, j}+8.700 x_{5, j} \\
-d_{7, j}^{+} \leq 7.000 .000
\end{aligned}
$$

\section{Pemodelan preemptive goal programming}

UD Citra Ayu Bali ingin memenuhi ketiga tujuan tersebut berdasarkan urutan tingkat kepentingan prioritas yang ingin dicapai. Berikut adalah urutan tingkat kepentingan prioritas dari ketiga tujuan yang ingin dicapai UD Citra Ayu Bali :

1. Prioritas pertama yaitu terpenuhinya target jumlah permintaan scrub yang akan diproduksi, sehingga tujuannya adalah meminimalkan angka penyimpangan / variabel deviasional di bawah sasaran $\left(d^{-}\right)$. Fungsi tujuan dari prioritas pertama menjadi : $\operatorname{Min} P_{1, j}\left(d_{1, j}^{-}+d_{2, j}^{-}+d_{3, j}^{-}+d_{4, j}^{-}+d_{5, j}^{-}\right)$, untuk $j=1,2,3, \ldots, 12$.

2. Prioritas kedua yaitu terpenuhinya target memaksimalkan keuntungan usaha dagang, sehingga tujuannya adalah meminimalkan angka penyimpangan / variabel deviasional di bawah sasaran $\left(d^{-}\right)$. Fungsi tujuan dari prioritas kedua menjadi :

$\operatorname{Min} P_{2, j}\left(d_{6, j}^{-}\right)$, untuk $j=1,2,3, \ldots, 12$.

3. Prioritas ketiga yaitu terpenuhinya target meminimalkan biaya produksi, sehingga tujuannya adalah meminimalkan angka penyimpangan / variabel deviasional di atas sasaran $\left(d^{+}\right)$. Fungsi tujuan dari prioritas ketiga menjadi :

$\operatorname{Min} P_{3, j}\left(d_{7, j}^{+}\right)$, untuk $j=1,2,3, \ldots, 12$.
Selanjutnya, berdasarkan persamaan (1.1) dibentuk model preemptive goal programming sebagai berikut:

\section{Fungsi Tujuan :}

\section{Fungsi Kendala :}

$$
\begin{array}{r}
\operatorname{Min} P_{1, j}\left(d_{1, j}^{-}+d_{2, j}^{-}+d_{3, j}^{-}+d_{4, j}^{-}+d_{5, j}^{-}\right) \\
+P_{2, j}\left(d_{6, j}^{-}\right)+P_{3, j}\left(d_{7, j}^{+}\right)
\end{array}
$$

\section{Kendala bahan baku}

Scrub kasar

$$
\begin{gathered}
10 x_{1, j}+10 x_{2, j}+10 x_{3, j}+10 x_{4, j}+10 x_{5, j} \\
\leq 10.000
\end{gathered}
$$

Ekstrak bunga chamomile

$$
\begin{gathered}
0,25 x_{1, j}+0,25 x_{2, j}+0,25 x_{3, j}+0,25 x_{4, j} \\
+0,25 x_{5, j} \leq 500
\end{gathered}
$$

Air

$$
\begin{array}{r}
250 x_{1, j}+250 x_{2, j}+250 x_{3, j}+250 x_{4, j} \\
+250 x_{5, j} \leq 200.000
\end{array}
$$

Bahan pembuat cream

$$
\begin{gathered}
62,5 x_{1, j}+62,5 x_{2, j}+62,5 x_{3, j}+62,5 x_{4, j} \\
+62,5 x_{5, j} \leq 35.000
\end{gathered}
$$

Pewarna Hijau

$$
0,05 x_{3, j}+0,05 x_{4, j} \leq 7
$$

Pewarna Merah Muda

Ekstrak Bengkoang

$$
0,05 x_{5, j} \leq 7
$$

Ekstrak Avocado

$$
0,25 x_{2, j} \leq 30
$$

Ekstrak Green Tea

$$
0,25 x_{3, j} \leq 125
$$

Ekstrak Strawberry

$$
0,25 x_{4, j} \leq 50
$$

Parfum Frangipani

$$
0,25 x_{5, j} \leq 200
$$

Parfum Bengkoang

Parfum Avocado

$$
1,25 x_{2, j} \leq 250
$$

Parfum Green Tea

$$
1,25 x_{3, j} \leq 125
$$

Parfum Strawberry

$$
1,25 x_{4, j} \leq 170
$$

$$
1,25 x_{5, j} \leq 185
$$

\section{Kendala sasaran}

Target jumlah permintaan masing-masing scrub yang akan diproduksi :

Scrub frangipani

$$
\begin{aligned}
& x_{1,1}+d_{1,1}^{-} \geq 31 \\
& x_{1,2}+d_{1,2}^{-} \geq 71 \\
& x_{1,3}+d_{1,3}^{-} \geq 50
\end{aligned}
$$




$$
\begin{aligned}
& x_{1,4}+d_{1,4}^{-} \geq 108 \\
& x_{1,5}+d_{1,5}^{-} \geq 145 \\
& x_{1,6}+d_{1,6}^{-} \geq 89 \\
& x_{1,7}+d_{1,7}^{-} \geq 9 \\
& x_{1,8}+d_{1,8}^{-} \geq 77 \\
& x_{1,9}+d_{1,9}^{-} \geq 7 \\
& x_{1,10}+d_{1,10}^{-} \geq 147 \\
& x_{1,11}+d_{1,11}^{-} \geq 7 \\
& x_{1,12}+d_{1,12}^{-} \geq 115
\end{aligned}
$$

Scrub bengkoang

$$
\begin{aligned}
& x_{2,1}+d_{2,1}^{-} \geq 52 \\
& x_{2,2}+d_{2,2}^{-} \geq 82 \\
& x_{2,3}+d_{2,3}^{-} \geq 71 \\
& x_{2,4}+d_{2,4}^{-} \geq 119 \\
& x_{2,5}+d_{2,5}^{-} \geq 114 \\
& x_{2,6}+d_{2,6}^{-} \geq 118 \\
& x_{2,7}+d_{2,7}^{-} \geq 25 \\
& x_{2,8}+d_{2,8}^{-} \geq 87 \\
& x_{2,9}+d_{2,9}^{-} \geq 16 \\
& x_{2,10}+d_{2,10}^{-} \geq 159 \\
& x_{2,11}+d_{2,11}^{-} \geq 19 \\
& x_{2,12}+d_{2,12}^{-} \geq 124
\end{aligned}
$$

Scrub avocado

$$
\begin{aligned}
& x_{3,1}+d_{3,1}^{-} \geq 53 \\
& x_{3,2}+d_{3,2}^{-} \geq 67 \\
& x_{3,3}+d_{3,3}^{-} \geq 129 \\
& x_{3,4}+d_{3,4}^{-} \geq 118 \\
& x_{3,5}+d_{3,5}^{-} \geq 118 \\
& x_{3,6}+d_{3,6}^{-} \geq 128 \\
& x_{3,7}+d_{3,7}^{-} \geq 20 \\
& x_{3,8}+d_{3,8}^{-} \geq 84 \\
& x_{3,9}+d_{3,9}^{-} \geq 21 \\
& x_{3,10}+d_{3,10}^{-} \geq 153 \\
& x_{3,11}+d_{3,11}^{-} \geq 13 \\
& x_{3,12}+d_{3,12}^{-} \geq 115
\end{aligned}
$$

\section{Scrub green tea}

$$
\begin{aligned}
& x_{4,1}+d_{4,1}^{-} \geq 42 \\
& x_{4,2}+d_{4,2}^{-} \geq 64 \\
& x_{4,3}+d_{4,3}^{-} \geq 67 \\
& x_{4,4}+d_{4,4}^{-} \geq 125 \\
& x_{4,5}+d_{4,5}^{-} \geq 109 \\
& x_{4,6}+d_{4,6}^{-} \geq 163 \\
& x_{4,7}+d_{4,7}^{-} \geq 28 \\
& x_{4,8}+d_{4,8}^{-} \geq 87 \\
& x_{4,9}+d_{4,9}^{-} \geq 13 \\
& x_{4,10}+d_{4,10}^{-} \geq 157 \\
& x_{4,11}+d_{4,11}^{-} \geq 17
\end{aligned}
$$

$$
x_{4,12}+d_{4,12}^{-} \geq 94
$$

Scrub strawberry

$$
\begin{aligned}
& x_{5,1}+d_{5,1}^{-} \geq 34 \\
& x_{5,2}+d_{5,2}^{-} \geq 74 \\
& x_{5,3}+d_{5,3}^{-} \geq 67 \\
& x_{5,4}+d_{5,4}^{-} \geq 107 \\
& x_{5,5}+d_{5,5}^{-} \geq 105 \\
& x_{5,6}+d_{5,6}^{-} \geq 108 \\
& x_{5,7}+d_{5,7}^{-} \geq 21 \\
& x_{5,8}+d_{5,8}^{-} \geq 77 \\
& x_{5,9}+d_{5,9}^{-} \geq 6 \\
& x_{5,10}+d_{5,10}^{-} \geq 144 \\
& x_{5,11}+d_{5,11}^{-} \geq 3 \\
& x_{5,12}+d_{5,12}^{-} \geq 79
\end{aligned}
$$

Target memaksimalkan keuntungan usaha

$$
\begin{aligned}
5.400 x_{1, j}+5.100 x_{2, j}+5.300 x_{3, j}+4.900 x_{4, j} \\
+ \\
\geq 4.300 x_{5, j}+d_{6, j}^{-} \\
\geq 4.500 .000
\end{aligned}
$$

Target meminimumkan biaya produksi

$$
\begin{aligned}
8.600 x_{1, j}+8.900 x_{2, j}+8.700 x_{3, j}+9.100 x_{4, j} \\
+8.700 x_{5, j}-d_{7, j}^{+} \\
\leq 7.000 .000
\end{aligned}
$$

$x_{i, j} \geq 0, \quad x_{i, j} \in N, \quad d_{i, j}^{-} \geq 0, d_{i, j}^{+} \geq 0, \quad$ untuk $i=1,2,3,4,5$ dan $j=1,2,3, \ldots, 12$.

Penyelesaian untuk model preemptive goal programming di atas menggunakan bantuan program Lindo.

\section{Hasil Preemptive Goal Programming}

Berdasarkan model preemptive goal programming yang telah dibuat, dengan menggunakan program Lindo maka diperoleh jumlah produksi optimal dari scrub UD Citra Ayu Bali sebagai berikut:

Tabel 2. Jumlah Produksi Optimal Scrub UD Citra Ayu Bali

\begin{tabular}{|c|c|c|c|c|c|c|}
\hline$(j)$ & $\left(x_{1}\right)$ & $\left(x_{2}\right)$ & $\left(x_{3}\right)$ & $\left(x_{4}\right)$ & $\left(x_{5}\right)$ & Jumlah \\
\hline 1 & 31 & 52 & 53 & 42 & 34 & 212 \\
\hline 2 & 148 & 120 & 76 & 64 & 140 & 548 \\
\hline 3 & 50 & 71 & 100 & 40 & 67 & 328 \\
\hline 4 & 108 & 119 & 100 & 40 & 107 & 474 \\
\hline 5 & 145 & 114 & 100 & 40 & 107 & 506 \\
\hline 6 & 89 & 118 & 100 & 40 & 108 & 455 \\
\hline 7 & 9 & 25 & 20 & 28 & 21 & 103 \\
\hline 8 & 77 & 87 & 53 & 87 & 77 & 381 \\
\hline 9 & 7 & 16 & 21 & 13 & 6 & 63 \\
\hline 10 & 147 & 120 & 100 & 40 & 140 & 547 \\
\hline 11 & 7 & 19 & 13 & 17 & 3 & 59 \\
\hline 12 & 115 & 120 & 100 & 40 & 79 & 454 \\
\hline
\end{tabular}


Selain itu diperoleh nilai deviasi dan pencapaian masing-masing prioritas pada tiap minggu yang ditampilkan dalam tabel berikut :

Tabel 3. Tabel Pencapaian Prioritas

\begin{tabular}{|c|c|c|c|}
\hline$j$ & $P_{1}$ & $P_{2}$ & $P_{3}$ \\
\hline 1 & $\begin{array}{l}\text { Tercapai } \\
d_{1,1}^{-}=0 \\
d_{2,1}^{-}=0 \\
d_{3,1}^{-}=0 \\
d_{4,1}^{-}=0 \\
d_{5,1}^{-}=0\end{array}$ & $\begin{array}{l}\text { Tidak tercapai } \\
\qquad \begin{array}{l}d_{6,1}^{-} \\
=3400500\end{array}\end{array}$ & $\begin{array}{l}\text { Tercapai } \\
d_{7,1}^{+}=0\end{array}$ \\
\hline 2 & $\begin{array}{l}\text { Tercapai } \\
d_{1,2}^{-}=0 \\
d_{2,2}^{-}=0 \\
d_{3,2}^{-}=0 \\
d_{4,2}^{-}=0 \\
d_{5,2}^{-}=0\end{array}$ & $\begin{array}{c}\text { Tidak tercapai } \\
d_{6,2}^{-}=1630400\end{array}$ & $\begin{array}{l}\text { Tercapai } \\
d_{7,2}^{+}=0\end{array}$ \\
\hline 3 & $\begin{array}{c}\text { Tidak } \\
\text { tercapai } \\
d_{1,3}^{-}=0 \\
d_{2,3}^{-}=0 \\
d_{3,3}^{-}=29 \\
d_{4,3}^{-}=27 \\
d_{5,3}^{-}=0\end{array}$ & $\begin{array}{c}\text { Tidak tercapai } \\
d_{6,3}^{-}=2786800\end{array}$ & $\begin{array}{l}\text { Tercapai } \\
d_{7,3}^{+}=0\end{array}$ \\
\hline 4 & $\begin{array}{c}\text { Tidak } \\
\text { tercapai } \\
d_{1,4}^{-}=0 \\
d_{2,4}^{-}=0 \\
d_{3,4}^{-}=18 \\
d_{4,4}^{-}=85 \\
d_{5,4}^{-}=0\end{array}$ & $\begin{array}{l}\text { Tidak tercapai } \\
d_{6,4}^{-}=2016800\end{array}$ & $\begin{array}{l}\text { Tercapai } \\
d_{7,4}^{+}=0\end{array}$ \\
\hline 5 & $\begin{array}{c}\text { Tidak } \\
\text { tercapai } \\
d_{1,5}^{-}=0 \\
d_{2,5}^{-}=0 \\
d_{3,5}^{-}=18 \\
d_{4,5}^{-}=85 \\
d_{5,5}^{-}=0\end{array}$ & $\begin{array}{l}\text { Tidak tercapai } \\
d_{6,5}^{-}=1842500\end{array}$ & $\begin{array}{l}\text { Tercapai } \\
d_{7,5}^{+}=0\end{array}$ \\
\hline 6 & $\begin{array}{c}\text { Tidak } \\
\text { tercapai } \\
d_{1,6}^{-}=0 \\
d_{2,6}^{2}=0 \\
d_{3,6}^{-}=28 \\
d_{4,6}^{-} \\
=123 \\
d_{5,6}^{-}=0\end{array}$ & $\begin{array}{l}\text { Tidak tercapai } \\
d_{6,6}^{-}=2119200\end{array}$ & $\begin{array}{l}\text { Tercapai } \\
d_{7,6}^{+}=0\end{array}$ \\
\hline
\end{tabular}

\begin{tabular}{|c|c|c|c|}
\hline 7 & $\begin{array}{l}\text { Tercapai } \\
d_{1,7}^{-}=0 \\
d_{2,7}^{-}=0 \\
d_{3,7}^{-}=0 \\
d_{4,7}^{-}=0 \\
d_{5,7}^{-}=0\end{array}$ & $\begin{array}{c}\text { Tidak tercapai } \\
d_{6,7}^{-}=3969400\end{array}$ & $\begin{array}{l}\text { Tercapai } \\
d_{7,7}^{+}=0\end{array}$ \\
\hline 8 & $\begin{array}{c}\text { Tidak } \\
\text { tercapai } \\
d_{1,8}^{-}=0 \\
d_{2,8}^{-}=0 \\
d_{3,8}^{-}=31 \\
d_{4,8}^{-}=0 \\
d_{5,8}^{-}=0\end{array}$ & $\begin{array}{c}\text { Tidak tercapai } \\
d_{6,8}^{-}=2525200\end{array}$ & $\begin{array}{l}\text { Tercapai } \\
d_{7,8}^{+}=0\end{array}$ \\
\hline 9 & $\begin{array}{l}\text { Tercapai } \\
d_{1,9}^{-}=0 \\
d_{2,9}^{-}=0 \\
d_{3,9}^{-}=0 \\
d_{4,9}^{-}=0 \\
d_{5,9}^{-}=0\end{array}$ & $\begin{array}{l}\text { Tidak tercapai } \\
d_{6,9}^{-}=4173800\end{array}$ & $\begin{array}{l}\text { Tercapai } \\
d_{7,9}^{+}=0\end{array}$ \\
\hline 10 & $\begin{array}{c}\text { Tidak } \\
\text { tercapai } \\
d_{1,10}^{-}=0 \\
d_{2,10}^{-} \\
=39 \\
d_{3,10}^{-} \\
=53 \\
d_{4,10}^{-} \\
=117 \\
d_{5,10}^{-}=5\end{array}$ & $\begin{array}{c}\text { Tidak tercapai } \\
d_{6,10}^{-}=1626200\end{array}$ & $\begin{array}{l}\text { Tercapai } \\
\begin{array}{l}d_{7,10}^{+} \\
=0\end{array}\end{array}$ \\
\hline 11 & $\begin{array}{l}\text { Tercapai } \\
d_{1,11}^{-}=0 \\
d_{2,11}^{-}=0 \\
d_{3,11}^{-}=0 \\
d_{4,11}^{-}=0 \\
d_{5,11}^{-}=0\end{array}$ & $\begin{array}{c}\text { Tidak tercapai } \\
d_{6,11}^{-}=4197200\end{array}$ & $\begin{array}{l}\text { Tercapai } \\
\begin{array}{l}d_{7,11}^{+} \\
=0\end{array}\end{array}$ \\
\hline 12 & $\begin{array}{c}\text { Tidak } \\
\text { tercapai } \\
d_{1,12}^{-}=0 \\
d_{2,12}^{-1}=4 \\
d_{3,12}^{-} \\
=15 \\
d_{4,12}^{-} \\
=54 \\
d_{5,12}^{-}=0\end{array}$ & $\begin{array}{c}\text { Tidak tercapai } \\
d_{6,12}^{-}=2122300\end{array}$ & $\begin{array}{l}\text { Tercapai } \\
d_{7,12}^{+} \\
=0\end{array}$ \\
\hline
\end{tabular}

Dari Tabel 3 dapat dilihat bahwa dari dua belas minggu, nilai deviasi pada prioritas 
pertama sama dengan 0 pada minggu pertama, kedua, ketujuh, kesembilan dan kesebelas. Ini berarti sasaran pada prioritas pertama yaitu target memenuhi permintaan kosumen tercapai, atau dengan kata lain jumlah scrub yang akan diproduksi sesuai dengan jumlah permintaan. Sasaran pada prioritas pertama tidak tercapai pada minggu ketiga, keempat, kelima, keenam, kedelapan, kesepuluh, kedua belas. Dengan kata lain jumlah scrub yang akan diproduksi tidak sesuai dengan jumlah permintaan. Hal ini diakibatkan karena persediaan bahan baku yang terbatas sedangkan permintaan akan scrub tersebut tinggi. Cara yang dapat dilakukan untuk mencapai sasaran tersebut adalah dengan menambah bahan baku produksi atau dengan membatasi jumlah permintaan scrub. Nilai deviasi pada prioritas kedua tidak sama dengan 0 pada setiap minggunya, ini berarti sasaran pada prioritas kedua yaitu target memaksimalkan keuntungan usaha tidak pernah tercapai. Hal ini diakibatkan karena banyaknya scrub yang akan diproduksi belum mencapai jumlah yang diperlukan untuk mendapatkan keuntungan minimal Rp 4.500.000.

Salah satu cara agar sasaran tercapai adalah dengan menurunkan target keuntungan yang diinginkan. Nilai deviasi pada prioritas ketiga sama dengan 0 pada setiap minggu, ini berarti sasaran pada prioritas ketiga yaitu merupakan target meminimalkan biaya produksi tercapai pada setiap minggunya atau dengan kata lain biaya produksi scrub pada setiap minggunya kurang dari Rp 7.000.000.

\section{KESIMPULAN DAN SARAN}

Berdasarkan pembahasan diperoleh bahwa jumlah produksi optimal kelima jenis body scrub UD Citra Ayu Bali selama 12 Minggu berturutturut dari Minggu pertama sampai Minggu kedua belas adalah 212 pieces, 548 pieces, 328 pieces, 474 pieces, 506 pieces, 455 pieces, 103 pieces, 381 pieces, 63 pieces, 547 pieces, 59 pieces, dan 454 pieces.

Pada penelitian ini tidak memperhatikan perubahan persediaan bahan baku yang berpengaruh pada perhitungan jumlah produk yang dapat di produksi, sehingga pada penelitian selanjutnya diharapkan memperhatikan perubahan persediaan bahan baku pada tiap periode. Selain itu kelebihan produksi pada periode sebelumnya juga sebaiknya ditambahkan ke perhitungan pada periode selanjutnya mengingat batas kadaluarsa produk ini adalah 1 Tahun.

\section{DAFTAR PUSTAKA}

Deviyanti, N. P., Tastrawati, N. K., \& Sumarjaya, I. W. (2015). Optimalisasi Produksi Dengan Preemptive Goal Programming (Studi Kasus: UD DodolMade Merta Tejakula, Singaraja). E-Jurnal Matematika Vol. 4 (4), 201-207.

Leachman, R. C. (2013, March 2). Industrial Engineering Design of Production Planning System for the Semiconductor Industry. Tersedia di http://courses.ieor.berkeley.edu/ieor130/Pro duction\%20Planning.pdf (Diakses pada 15 Januari 2017)

Siswanto. (2007). Operation Research (1st ed.). Jakarta: Erlangga.

Surachman, \& Astuti, M. (2015). Operation Research (2nd ed.). Malang: Media Nusa Creative. 